Original Research Article

\title{
Prescribing pattern of oral anti-diabetic agents in type 2 diabetes mellitus patients in a tertiary care hospital
}

\author{
Taruna Sharma $^{1}$, Rajit Sahai ${ }^{1 *}$, Suman Bala ${ }^{1}$, Dilip C. Dhasmana ${ }^{1}$, Nidhi Kaeley ${ }^{2}$
}

${ }^{1}$ Department of Pharmacology,

${ }^{2}$ Department of General Medicine, Himalayan Institute of Medical Sciences, Dehradun, Uttarakhand, India

Received: 10 March 2018 Accepted: 03 April 2018

*Correspondence to:

Dr. Rajit Sahai,

Email: sahairajit@gmail.com

Copyright: (C) the author(s), publisher and licensee Medip Academy. This is an openaccess article distributed under the terms of the Creative Commons Attribution NonCommercial License, which permits unrestricted noncommercial use, distribution, and reproduction in any medium, provided the original work is properly cited.

\begin{abstract}
Background: Prescription pattern studies are a tool for assessing the prescribing, dispensing and distribution of medicines. The main aim of assessing prescribing pattern is to facilitate rational use of medicines. So the main aim of the study was to assess the prescribing pattern of oral anti-diabetic agents in type 2 diabetes mellitus, to assess the rationality of the prescribed drugs and also to assess the pattern of co-morbid conditions associated with type 2 diabetes mellitus in a tertiary care hospital.

Methods: This cross sectional study was conducted in the Department of Pharmacology in collaboration with Department of General Medicine. Study was conducted from 1st June 2016 to 31st Aug 2016 (3 months). A total of 100 patients were enrolled after taking written informed consent. A structured case recording form was used to record demographic details and prescription details. The rationality of prescriptions was assessed using American Diabetes Association guidelines 2015.

Results: Majority of the patients were prescribed combination therapy (54\%) followed by monotherapy (46\%). Oral anti-diabetic agents used as monotherapy other than metformin were inappropriate. Among the patients receiving combination therapy majority were receiving a fixed dose combination which were inappropriate.

Conclusions: Majority of the patients were receiving fixed dose combinations without justifiable pharmacokinetic/pharmacodynamic benefits. Such kinds of studies are required to improve rationality of prescription of drugs, decreasing morbidity and mortality of patients and decreasing the cost of treatment.
\end{abstract}

Keywords: Oral anti-diabetic agents, Prescribing pattern, Type 2 diabetes mellitus

\section{INTRODUCTION}

Medically unsuitable, ineffective and non-economical use of pharmaceutical products is commonly observed in clinical practice throughout the world and especially in developing countries. ${ }^{1}$ The rational use of drugs requires the patients to receive medicines appropriate to their clinical needs, in doses that meet their individual requirements, for an adequate period of time and at the lowest possible cost. Rational prescribing forms the foundation of successful implementation of the rational use of drugs. ${ }^{2}$

Diabetes mellitus (DM) is a chronic disease characterized by insulin deficiency, with the resultant hyperglycemia and insulin resistance, leading to macro and micro vascular complications. ${ }^{3}$ Modern principles of management of diabetes focus on screening high risk individuals, disease prevention in pre-diabetics and proactive treatment of individuals in diabetic state. ${ }^{4}$ Current recommendations include a trial of diet and exercise for as first line therapy for the treatment of patients with type 2 diabetes. The 
pharmacotherapy of diabetes mellitus includes treatment with drugs such as oral anti-diabetic agents and insulin. ${ }^{5}$ Co-morbidity has been shown to intensify health care utilization and increase medical care costs for patients with diabetes. Prescribing pattern studies are important tools for assessing the prescription, dispensing and distribution of medicines. The main aim of assessing prescribing pattern is to facilitate rational use of medicines. Irrational prescribing increases the cost of medical treatment, nonadherence to drug therapy, which can result in complications especially in diabetes due to uncontrolled blood glucose levels and also lead to rise in drug and health care costs. ${ }^{3}$ Therefore, it is important to periodically assess the prescribing behaviour of physicians working in health facilities, in order to undertake corrective measures effectively. ${ }^{6}$ The present study was designed to study the prescribing pattern of oral anti-diabetic agents in DM in a tertiary care hospital to assess the rationality of the prescribed drugs and also to assess the pattern of comorbid conditions associated.

\section{METHODS}

This cross sectional study was designed to assess the prescribing pattern of oral anti-diabetic agents among type 2 diabetics in a tertiary care hospital. It was conducted in the department of Pharmacology in collaboration with department of General Medicine for a period of 3 months from June 2016 to August 2016. A total of 100 patients on oral anti-diabetic agents were recruited in the study from the medicine OPD after taking written informed consent (Based on the number of diabetic patients attending the OPD/day) and getting clearance from the Institutional Ethics Committee. Once included in the study the demographic details of all the patients were recorded from the patient's outpatient card along with the number of drugs they were being prescribed. The associated comorbid conditions, if any were also recorded. The rationality of the prescription for oral anti-diabetic agents was assessed by using treatment guidelines as mentioned in American Diabetes Association (ADA) guidelines $2015^{7}$

\section{Inclusion criteria}

- $\quad$ Patients of Type 2 DM

- Patients of either sex of $>18 y$ rs of age

- Patients on oral anti-diabetic agents

\section{Exclusion criteria}

- $\quad$ Patients of Type 1 DM

- Patients of Type 2 DM on insulin treatment

- Pregnant/ lactating females

\section{Statistical analysis}

Data was entered using Microsoft Excel. Quantitative variables were expressed as Mean \pm SD. Descriptive statistics was used to express the data in the form of percentage, bar charts etc.

\section{RESULTS}

The demographic details of the patients are listed in Table 1. Of the 100 patients 52 were males and 48 were females. The mean age of the patients was $47.99 \pm 13.37$. $40 \%$ patients had a positive family history of type 2 diabetes mellitus and 47 were suffering from an associated comorbid condition (Table 1).

Table 1: Demographic details.

\begin{tabular}{|ll|}
\hline Parameters & Number/Percentage \\
\hline Number of prescriptions & 100 \\
\hline Male/Female & $52 / 48$ \\
\hline Mean age* & $47.99 \pm 13.37$ \\
\hline Duration of diabetes mellitus & 6 months- yrs \\
\hline $\begin{array}{l}\text { Family history of diabetes } \\
\text { mellitus }\end{array}$ & $40 \%$ \\
\hline $\begin{array}{l}\text { Average number of drugs per } \\
\text { prescription* }\end{array}$ & $5.23 \pm 2.23$ \\
\hline $\begin{array}{l}\text { Patients suffering from co- } \\
\text { morbid conditions: }\end{array}$ & 47 \\
\hline Hypertension & 36 \\
\hline Hypothyroidism & 6 \\
\hline Ischaemic heart disease & 6 \\
\hline Respiratory disorders & 6 \\
\hline Migraine & 3 \\
\hline Osteoarthritis & 3 \\
\hline Dyslipidemia & 2 \\
\hline Seizure disorder & 1 \\
\hline (Mean \pm S.D.) & \\
\hline
\end{tabular}

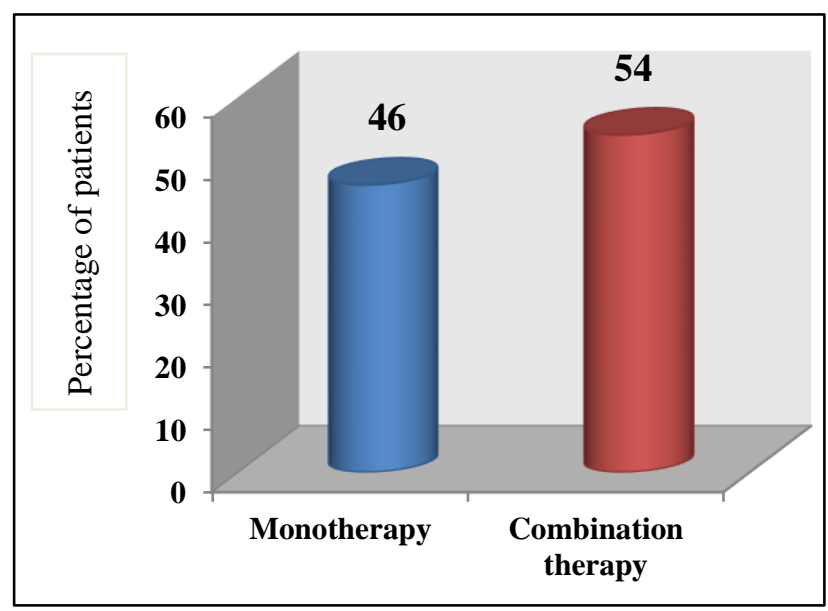

Figure 1: Percentage of patients receiving monotherapy and combination therapy for diabetes.

A total of $46 \%$ of patients were prescribed monotherapy and $54 \%$ of patients were being prescribed a combination therapy (Both dual and triple drug therapy) for diabetes (Figure 1). 
Amongst monotherapy metformin (biguanide) was maximally prescribed. Other classes of drugs used as monotherapy were pioglitazone (thiazolidinedione) and glimepiride (sulfonylurea). In the dual therapy, a combination of metformin with glimepiride/glipizide (sulfonylurea) was maximally prescribed, followed by pioglitazone, voglibose ( $\alpha$-glucosidase inhibitor) and sitagliptin (DPP-4 inhibitor). In the triple drug therapy addition of sitagliptin/vildagliptin (DPP-4 inhibitor) to the combination of metformin and glimepiride was maximally observed followed by voglibose and pioglitazone (Table 2).

\section{Table 2: Oral anti-diabetic agents prescribed in type-2 diabetic patients as monotherapy and combination therapy.}

\begin{tabular}{|c|c|c|c|}
\hline Drug groups & $\begin{array}{l}\text { Mono- } \\
\text { therapy } \\
\mathrm{n}=46(\%)\end{array}$ & $\begin{array}{l}\text { Dual } \\
\text { therapy } \\
\mathrm{n}=28 \\
(\%)\end{array}$ & $\begin{array}{l}\text { Triple } \\
\text { drug } \\
\text { therapy } \\
\mathrm{n}=26(\%)\end{array}$ \\
\hline Biguanides & $41(89)$ & $\begin{array}{l}28 \\
(100)\end{array}$ & $26(100)$ \\
\hline Sulfonylureas & $2(4)$ & $20(71)$ & $26(100)$ \\
\hline Thiazolidinediones & $3(7)$ & $4(14)$ & $2(8)$ \\
\hline DPP-4 inhibitors & 0 & $2(7)$ & $13(50)$ \\
\hline $\begin{array}{l}\alpha \text {-glucosidase } \\
\text { inhibitors }\end{array}$ & 0 & $2(7)$ & $11(42)$ \\
\hline
\end{tabular}

Among the patients receiving combination therapy (54\%), majority were receiving a fixed dose combination (FDC). $38(70.4 \%)$ FDCs prescribed in both dual and triple drug therapy were found to be inappropriate (Table 3).

Table 3: Percentage of inappropriate FDCs.

\begin{tabular}{|llll|}
\hline $\begin{array}{l}\text { Parameters for } \\
\text { inappropriate } \\
\text { FDCs }\end{array}$ & $\begin{array}{l}\text { Dual } \\
\text { therapy } \\
\mathbf{n = 1 6}(\%)\end{array}$ & $\begin{array}{l}\text { Triple drug } \\
\text { therapy } \\
\mathbf{n = 2 2}(\%)\end{array}$ & $\begin{array}{l}\text { Total } \\
\mathbf{n = 3 8} \\
(\%)\end{array}$ \\
\hline Dosage & $10(62)$ & $13(59)$ & $23(61)$ \\
\hline $\begin{array}{l}\text { Frequency of } \\
\text { administration }\end{array}$ & $6(38)$ & $9(41)$ & $15(39)$ \\
\hline Total & 16 & 22 & 38 \\
\hline
\end{tabular}

In addition each drug was prescribed by its brand name rather than its generic name which was not in accordance with the recommendations by the Medical council of India. $^{8}$

\section{DISCUSSION}

In budding markets of India the impact of high power salesmanship is enormous. It is observed generally that clinicians often are influenced by pharmaceutical companies for prescribing drugs and the patients who are at the receiving end often bear the cost of expensive and inappropriate medical treatment. Irrational prescribing of drugs is a major concern in many developing countries especially in India. This in the long run can endanger the health status of people and the health economics of the country.

A total of 100 patients were included in the study which showed 52\% male predominance among type 2 diabetics (Table 1) which is similar to results obtained by Haghighatpanah et al. ${ }^{9}$ The mean age of the patients in this study was $47.99 \pm 13.37$ yrs. A study by Upadhyay DK et al, in Nepal showed mean age $56.9 \pm 12.6$ yrs. ${ }^{10}$

Results of present study showed that the average number of drugs per prescription were $5.23 \pm 2.23$ (Table 1) which was lesser compared to study by Patel B et al 7.58 $\pm 2.49 .{ }^{11}$ The family history of diabetes was positive in $40 \%$ of patients in this study and hypertension was the most common co-morbid condition $(57 \%)$. (Table 1 ) in contrast to study by Patel B et al, which also showed positive correlation of family history $(35.1 \%)$ and hypertension $(70.2 \%)$ as the commonest co-morbid condition. ${ }^{12}$

Metformin (biguanide) has advantages over insulin secretagogues by decreasing excess hepatic gluconeogenesis without raising insulin levels. It seldom leads to hypoglycemia when used as a monotherapy. Metformin independently $(89 \%)$ and in combination (54\%) (Table 2) was the most commonly prescribed antidiabetic drug in the present study, in line with findings of Upadhyay DK et al. ${ }^{10}$

Metformin is considered an ideal first line agent for the treatment of Type 2 diabetes also because the cost of metformin is low, thus making it reasonable for the patients in economically weak countries like India. Other classes of drugs used as monotherapy were pioglitazone (thiazolidinedione, 7\%) and glimepiride (sulfonylurea, 4\%) (Table 2). They were being used in patients without any contra-indication to metformin and they were not found to be in accordance with treatment guidelines. ${ }^{7}$

As diabetes progresses, functional decrease in beta cell function is evident, which presses the need for combination therapy. Therefore, combination modalities have become an integral part of diabetes management. The main aim for combination therapy is to provide additional effects with different mechanisms of action and to allow lower doses for disease management. Consistent with the same, in the present study, majority (54\%) of the patients were receiving combination therapy among which maximum were on dual therapy $(52 \%)$ followed by triple drug therapy $(48 \%)$.

Metformin in combination with sulfonylureas (glimepiride/glipizide) was the most common combination in dual therapy (Table 2), followed by pioglitazone, voglibose ( $\alpha$-glucosidase inhibitor) and sitagliptin (DPP-4 inhibitor). A similar study as ours by Al Khaja KA et al, concluded the same. ${ }^{12}$ In triple drug therapy metformin along with sulfonylureas and DPP-4 inhibitors as add on therapy was the commonest combination prescribed followed by voglibose and pioglitazone. This does not 
correspond to the results by Haghighatpanah et al, showing voglibose being the commonest choice as add on therapy to metformin and glimepiride. ${ }^{9}$

In both dual and triple therapy, it was found that initial drugs were not escalated to their maximum tolerated dose before adding another drug in the course of therapy. This was not found to be in agreement with the treatment guidelines. $^{7}$

In the treatment of diabetes mellitus, the aim of the commonly employed FDC products is to provide rationale drug regulatory mechanism and enhance drug therapeutic effectiveness. The FDCs are justified when they demonstrate clear benefits which are supported by scientific evidence.

The FDCs manufactured without thoroughness can lead to problems of inadequate dosage leading to inadequate glycemic control and fall in adherence of the patient. A total of $38(70.4 \%)$ FDCs were prescribed in patients receiving combination therapy which were found to be inappropriate based on dosage and frequency of administration. In contrast study by Santra D et al, showed $39.46 \%$ oral anti-diabetic FDCs to be appropriate. ${ }^{13}$

It is advisable to prescribe drugs by generic name for cost effective utilization. In this study, all drugs were prescribed by brand name suggesting popularity of the brands among the physician and influence of pharmaceutical companies on the physician. A study by Agarwal, et al also showed similar results. ${ }^{14}$

\section{CONCLUSION}

To conclude majority of the patients were receiving combination therapy. Among them majority were receiving FDCs which were inappropriate without justifiable dosage/frequency of administration. Such kinds of studies are required to improve rationality of the prescribed drugs, decreasing morbidity and mortality of patients and decreasing the cost of treatment. Further studies with a longer duration of study and a larger sample size are needed to have a larger impact on the prescribing pattern. Limitations of our study were short duration of study and a small sample size.

\section{ACKNOWLEDGEMENTS}

Authors would like to thank the management of Himalayan Institute of Medical Sciences for helping them in completion of the study. Authors also like to thank the faculty of Department of Pharmacology, HIMS for smooth conduct of the study. A study is not complete without the co-operation of author's fellow colleagues during the study.

Funding: No funding sources

Conflict of interest: None declared
Ethical approval: The study was approved by the Institutional Ethics Committee

\section{REFERENCES}

1. Ansari KU, Singh S, Pandey RC. Evaluation of prescribing pattern of doctors for rational drug therapy. Indian J Pharmacol. 1998;30:43-6.

2. Jain S, Upadhyaya P, Goyal J, Kumar A, Jain P, Seth $\mathrm{V}$, et al. A systematic review of prescription pattern monitoring studies and their effectiveness in promoting rational use of medicines. Perspectives in Clinical Research. 2015;6(2):86-90.

3. Patel A, MacMahon S, Chalmers J, Neal B, Billot L, Woodward. M et al. Intensive Blood Glucose Control and Vascular Outcomes in patients with Type 2 Diabetes. NEJM. 2008;358:2560-72.

4. Unger J. Current strategies for evaluating, monitoring, and treating type 2 diabetes mellitus. Am J Med 2008;121(6 Suppl):S3-8.

5. American Diabetes Association. The pharmacological treatment of hyperglycemia in NIDDM. Diabetes Care. 1995;18:1510-8.

6. Meyer TA. Improving the quality of the order-writing process for inpatient orders and outpatient prescriptions. Am J Health-Syst Pharm. 2000;57 (Suppl 4):S18-22.

7. American Diabetes Association. Approaches to glycemic treatment. Diabetes Care. 2015;38:S41-8.

8. Medical Council of India. Code of ethics regulation 2002. Available at: http://www.mciindia.org/RulesandRegulations/Codeo fMedicalEthicsRegulations2002.aspx/ accessed on 19th January 2016.

9. Haghighatpanah M, Thunga G, Jha A, Mallayasamy S. Study on prescribing pattern of anti-diabetic drugs among type 2 diabetes patients with complication in south indian teaching hospital. Asian J Pharm Clin Res. 2016;9(Suppl1):194-7.

10. Upadhyay DK, Palaian S, Shankar PR, Mishra P, Sah AK. Prescribing Pattern in Diabetic Outpatients in a Tertiary Care Teaching Hospital in Nepal. Journal of Clinical and Diagnostic Research. 2007;3:248-55.

11. Patel B, Oza B, Patel PK, Malhotra DS, Patel JV. Pattern of antidiabetic drugs use in type-2 diabetic patients in a medicine outpatient clinic of a tertiary care teaching hospital. Int $\mathbf{J}$ Basic Clin Pharmacol. 2013;2(4):485-91.

12. Al Khaja KA, Sequeira RP, Mathur VS. Prescribing patterns and therapeutic implications for diabetic hypertension in Bahrain. Ann Pharmacother. 2001;35(11):1350-9.

13. Santra D, Totade S. Prescribing trends of antidiabetic fixed dose combination in a rural tertiary care teaching hospital in central India: An observational, cross sectional study. Research Journal of Pharmacology and Pharmacodynamics. 2015;7(1):19-22.

14. Agarwal AA, Jadhav RP, Deshmukh AY. Prescribing pattern and efficacy of anti diabetic drugs in maintaining optimal glycemic levels in diabetic 
patients. Journal of Basic and Clinical Pharmacy. 2014;5(3):79-83.
Cite this article as: Sharma T, Sahai R, Bala $S$, Dhasmana DC, Kaeley N. Prescribing pattern of oral anti-diabetic agents in type 2 diabetes mellitus patients in a tertiary care hospital. Int J Basic Clin Pharmacol 2018;7:956-60. 